\title{
Density Functional Theory Study on Triphenylamine-based Dye Sensitizers Containing Different Donor Moieties
}

\author{
Jie Xu, ${ }^{\dagger}, *$ Lei Wang, ${ }^{\dagger}$ Guijie Liang, ${ }^{\dagger, t}$ Zikui Bai, ${ }^{\dagger}$ Luoxin Wang, ${ }^{\dagger}$ Weilin Xu, and Xiaolin Shen ${ }^{\dagger}$ \\ ${ }^{\dagger}$ Key Lab of Green Processing \& Functional Textiles of New Textile Materials, Ministry of Education, Wuhan Textile \\ University, 430073,Wuhan, China. ${ }^{*}$ E-mail: xujie0@ustc.edu \\ ${ }^{*}$ College of Materials Science \& Engineering, Xi'an Jiao tong University, 710049, Xi'an, China \\ Received May 28, 2010, Accepted July 16, 2010
}

\begin{abstract}
Density functional theory (DFT) and time-dependent DFT (TD-DFT) calculations have been employed to investigate the molecular structures and absorption spectra of two dyes containing diphenylaniline and 4-diphenylamino-diphenylaniline as donor moiety (TPA1 and TPA3). The geometries indicate that the strong conjugation is formed in the dyes. The electronic structures suggest that the intramolecular charge transfer from the donor to the acceptor occurs, and the electron-donating capability of 4-diphenylamino-diphenylaniline is stronger than that of diphenylaniline. The computed highest occupied molecular orbital (HOMO) energy levels are -5.31 and $-4.90 \mathrm{eV}$, while the lowest unoccupied molecular orbital (LUMO) energies are -2.29 and $-2.26 \mathrm{eV}$ for TPA1 and TPA3, respectively, revealing that the interfacial charge transfer between the dyes and the semiconductor electrode are electron injection processes from the photonexcited dyes to the semiconductor conduction band. Furthermore, all the experimental absorption bands of TPA1 and TPA3 have been assigned according to the TDDFT calculations.
\end{abstract}

Key Words: Triphenylamine, Dye-sensitized solar cells, Density functional theory, Molecular structures, Absorption spectra

\section{Introduction}

Converting solar energy into electricity is generally regarded as the most prospective method to solve the global energy crisis, owing to its huge reserves and pollution-free character. The commercially available solar cells are currently based on inorganic silicon semiconductors. However, their large-scale application has been limited due to the price of high-purity silicon. Organic solar cells, therefore, appear to be a highly promising and cost-effective candidate for the photovoltaic energy industry. In this context, dye-sensitized solar cells (DSSCs) have received widespread attention in recent years because of their high solar-to-electric conversion efficiencies and low costs. ${ }^{1-6}$ The most successful sensitizers employed in these cells are ruthenium polypyridyl complexes, yielding conversion efficiencies up to $11-12 \%$ under air mass (AM) 1.5 irradiation. ${ }^{6}$ However, Ru complexes contain a heavy metal, which is undesirable from point of view of the environmental aspects. ${ }^{7}$ Moreover, the process to synthesize the complexes is complicated and costly. In addition to Ru complexes, metal-free organic dyes as sensitizers are also under intensive investigation due to their high molar extinction coefficients, flexible structural modifications and low costs, and to date some of them have reached good efficiencies. $^{8-15}$

In DSSCs, dye molecules first absorb visible or near infrared (IR) light, accompanied by the excitation of electrons to the excited states. The excited electrons subsequently are injected into the conduction band (CB) of the semiconductor electrode (typically $\mathrm{TiO}_{2}$ ), and then transfer to the anode by electron diffusion through the disordered network of $\mathrm{TiO}_{2}$ nanoparticles. The oxidized dye molecules are regenerated by the iodide redox couple or hole-transporter with the positive charge being trans- ported from the electrolyte to the platinum counter electrode. Therefore, the performance of DSSC strongly depends on the following factors: (1) Absorption efficiency of the dye sensitizer for solar light spectrum; (2) Electron injection probability from the excited state of the dye sensitizer to $\mathrm{TiO}_{2}$ (Efficiency of the charge separation); (3) Electron transfer probability from the electrolyte to the oxidized dye. ${ }^{3}$ All these factors are closely associated with the ground and excited electronic states of the dye sensitizer. From this point of view, it is imperative to investigate the electronic structures of the dye molecules for understanding the mechanism of the charge separation and transfer, which are the key processes in this type of solar cells. In order to design and synthesize more efficient dyes, it is also necessary to understand the electronic structures of the existing efficient sensitizers.

Density functional theory (DFT) has emerged as a reliable standard tool for the theoretical treatment of molecular structures and electronic absorption spectra. Its time-dependent extension called time-dependent DFT (TD-DFT) can give reliable values for valence excitation energies with the standard exchange-correlation functionals. The computational cost of TDDFT calculation is comparative to that of a Hartree-Fock based single excitation theory, such as, configuration interaction singles (CIS) or time-dependent Hartree-Fock (TD-HF) method and maintains a uniform accuracy for open-shell and closedshell systems. In recent years, DFT has been extensively used to study the structures and absorption spectra of sensitizers for DSSCs. ${ }^{4,16-32}$

Triphenylamine has been widely used as an electron donor for metal-free organic sensitizers due to its excellent electrondonating capability and aggregation resistant nonplanar molecular configuration. ${ }^{33}$ Aggregation can give rise to self-quench- 
ing, instability of the sensitizer, and reduce the electron injection efficiency, resulting in low conversion efficiency of the DSSCs. Recently, two sensitizers containing different triphenylamines as electron donor moiety, a cyanoacrylic acid as acceptor and anchoring group, (2Z)-2-cyano-3-[4-(diphenylamino)phenyl] acrylic acid (TPA1) and (2Z)-2-cyano-3-\{4-[[4-(diphenylamino)-phenyl](phenyl)amino]phenyl $\}$ acrylic acid (TPA3) were synthesized, yielding overall conversion efficiencies of $2.51 \%$ and $4.12 \%$, respectively, ${ }^{34}$ which experimentally proves that the donor moiety plays a crucial role in determining the conversion efficiency of DSSC. To theoretically understand the donor effects and the sensitized mechanism at a molecular level, the geometric and electronic structures of the triphenylamine dyes TPA1 and TPA3 were studied in detail using DFT, and the absorption spectra were investigated according to TD-DFT calculations.

\section{Computational Method}

All the calculations were performed with the Gaussian 03 program package. ${ }^{35}$ The ground-state geometries were fully optimized without any symmetry constrains at the DFT level with Becke's ${ }^{36}$ three parameters hybrid functional and Lee, Yang and Parr's correlational functional B3LYP ${ }^{37}$ using a standard 6-31g(d) basis set on all atoms. A full natural bond orbital (NBO) analysis was obtained by using the $\mathrm{POP}=\mathrm{NBO}$ keyword. The excitation energies and oscillator strengths for the lowest 30 singlet-singlet transitions at the optimized geometry in the ground state were obtained by TD-DFT calculations using the same basis set as for the ground state and three kinds of hybrid functional B3LYP, PBE1PBE and MPW1PW91, respectively. According to the calculated results, the UV-vis absorption spectra were simulated by means of the SWizard program (Revision $4.6)^{38}$ using a Gaussian convolution with the full width at halfmaximum of $3000 \mathrm{~cm}^{-1}$. Solvation effects were introduced by the SCRF method, via the conductor polarizable continuum model (CPCM $)^{39,40}$ implemented in the Gaussian program, for both geometry optimizations and TD-DFT calculations.

\section{Results and Discussion}

Ground-state geometries. One of the major goals in the design of dye sensitizers for solar cells is to create molecular structures favoring the absorption in the visible/near IR region and possessing appropriate excited state able to directly inject into the $\mathrm{CB}$ of the semiconductor electrode (typically $\mathrm{TiO}_{2}$ ). Donor-acceptor (D-A) dyes which contain both electron-donating (D) and electron-accepting (A) units connected by covalent links (usually $\pi$ conjugated) have been developed to enhance both the absorption at long wavelengths (low energies) and the extinction coefficients. The photoabsorption properties of a D-A dye are associated with intramolecular charge transfer (ICT) excitation from the donor to the acceptor moiety of the dye, resulting in efficient electron transfer through the acceptor moiety (such as carboxyl or hydroxyl) from the excited dye into the semiconductor $\mathrm{CB}$. The charge transfer or separation between the electron donor and acceptor moieties in the excited dye may facilitate rapid electron injection from the dye molecule into
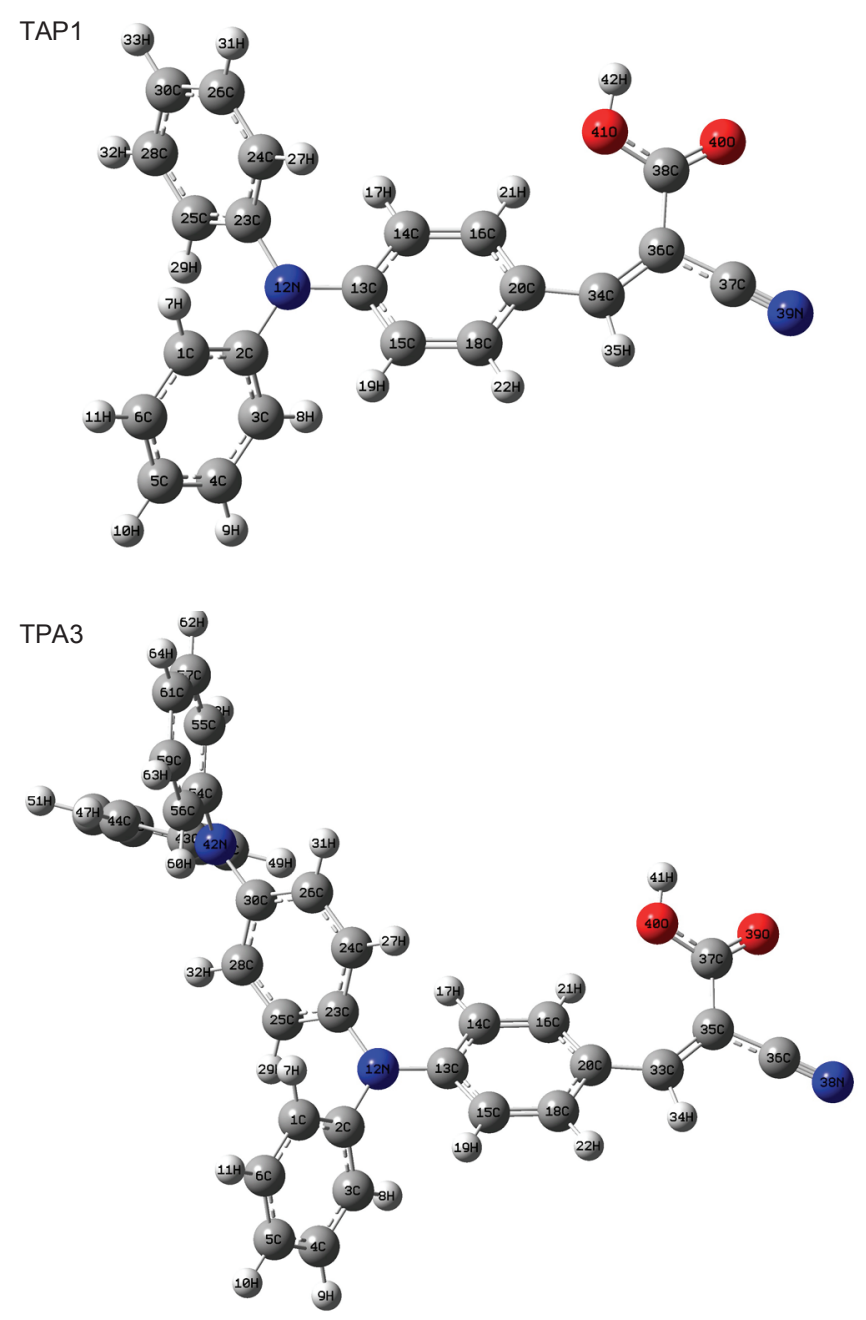

Figure 1. Optimized ground-state geometries of TPA1 and TPA3.

the semiconductor $\mathrm{CB}$, so that it would be expected to separate the cationic charge effectively from the semiconductor surface and to restrict recombination between the photoelectron (the injected electron) and the oxidized dye sensitizer efficiently.

The dyes TPA1 and TPA3 considered in this work share the same acceptor moiety, while two different donors were used: a diphenylaniline group in the case of TPA1 and a 4-diphenylamino-diphenylaniline group for TPA3. The optimized groundstate geometries of TPA1 and TPA3 are shown in Fig. 1, and the selected bond lengths, bond angles and dihedral angles are listed in Table 1. All the CC lengths in the phenyl and vinylene groups are between the distance of a single bonded $\mathrm{C}-\mathrm{C}$ and a double bonded $\mathrm{C}=\mathrm{C}$, implying that there exists extensive delocalization throughout the molecule. The acceptor and donor moieties are practically identical in the two dyes, as demonstrated by the very similar computed internal structural parameters. However, as to TPA3, the corresponding bond lengths and dihedral angels for the diphenylamino unit are significantly different with those for the diphenylaniline, which is attributed to the increased distance and thus the weakened effect between the donor and acceptor moieties.

The donor and acceptor moieties are $\pi$-conjugated, although these groups are not fully coplanar but tilted by about $23.9^{\circ}$ 
Table 1. Selected bond lengths (in angstrom), bond angles (in degree) and dihedral (in degree) of TPA1 and TPA3

\begin{tabular}{|c|c|c|c|}
\hline \multirow{2}{*}{$\begin{array}{r}\text { TPA1 } \\
\mathrm{C} 1-\mathrm{C} 2\end{array}$} & \multicolumn{3}{|c|}{ TPA3 } \\
\hline & 1.4015 & $\mathrm{C} 1-\mathrm{C} 2$ & 1.4012 \\
\hline $\mathrm{N} 12-\mathrm{C} 2$ & 1.4334 & N12-C2 & 1.4340 \\
\hline $\mathrm{N} 12-\mathrm{C} 23$ & 1.4337 & $\mathrm{~N} 12-\mathrm{C} 23$ & 1.4329 \\
\hline N12-C13 & 1.3913 & N12-C13 & 1.3893 \\
\hline $\mathrm{C} 13-\mathrm{C} 14$ & 1.4176 & $\mathrm{C} 13-\mathrm{C} 14$ & 1.4185 \\
\hline C20-C34 & 1.4404 & $\mathrm{C} 20-\mathrm{C} 33$ & 1.4393 \\
\hline \multirow[t]{4}{*}{ C34-C36 } & 1.3791 & C33-C35 & 1.3799 \\
\hline & & N42-C54 & 1.4246 \\
\hline & & $\mathrm{N} 42-\mathrm{C} 43$ & 1.4251 \\
\hline & & N42-C30 & 1.4156 \\
\hline C13-N12-C2 & 121.3 & C13-N12-C2 & 121.2 \\
\hline C13-N12-C23 & 121.1 & C13-N12-C23 & 121.4 \\
\hline \multirow[t]{3}{*}{ C20-C34-C36 } & 135.2 & $\mathrm{C} 20-\mathrm{C} 33-\mathrm{C} 35$ & 134.8 \\
\hline & & C30-N42-C43 & 120.3 \\
\hline & & C30-N42-C54 & 120.5 \\
\hline C2-N12-C13-C15 & -23.7 & C2-N12-C13-C15 & -21.9 \\
\hline C3-C2-C13-C15 & -64.1 & C3-C2-C13-C15 & -64.4 \\
\hline C23-N12-C13-C14 & -24.4 & C23-N12-C13-C14 & -22.8 \\
\hline C16-C20-C34-C36 & 16.7 & C16-C20-C33-C35 & 17.7 \\
\hline C16-C20-C36-C37 & -156.1 & $\mathrm{C} 16-\mathrm{C} 20-\mathrm{C} 35-\mathrm{C} 36$ & -154.5 \\
\hline \multirow[t]{4}{*}{$\mathrm{C} 16-\mathrm{C} 20-\mathrm{C} 38-\mathrm{O} 41$} & 40.7 & $\mathrm{C} 16-\mathrm{C} 20-\mathrm{C} 37-\mathrm{O} 40$ & 42.7 \\
\hline & & $\mathrm{C} 43-\mathrm{N} 42-\mathrm{C} 30-\mathrm{C} 28$ & -36.8 \\
\hline & & $\mathrm{C} 45-\mathrm{C} 43-\mathrm{C} 30-\mathrm{C} 28$ & -70.0 \\
\hline & & C54-N42-C30-C25 & -37.1 \\
\hline
\end{tabular}

and $25.5^{\circ}$ for TPA 1 and TPA3 (see C16-C20-C36-C37 and C16C20-C35-C36 in Table 1) due mainly to steric repulsion between the rings. The delocalization in the conjugate assembly is beneficial to the ICT and to the stability of the molecule. The anchoring carboxylic group (-COOH) is geometrically distorted from the $\pi$ extended system of the molecule (Fig. 2) as demonstrated by the relatively large C16-C20-C38-O41 and C16-C20-C37O40 values. Therefore, assuming a bidentate bind of the carboxyl group to the surface it has been inferred that the $\pi$ system of these dyes most probably lay parallel to the supporting semiconductor's surface. ${ }^{41}$

Electronic structures. The dipole moments of TPA1 and TPA3 are 14.60 and 15.41, respectively, indicating that these two triphenylamine dyes are highly polar molecules. The values of quadrupole moments for TPA1 and TPA 3 are listed in Table 2 , where the average of the diagonal quadrupole moment tensor elements $Q_{i i}$ and unique quadrupole moment $Q$ are defined as follows:

$$
\begin{gathered}
Q_{i i}=\left(Q_{X X}+Q_{Y Y}+Q_{Z Z}\right) / 3 \\
Q=Q_{X X}-Q_{Y Y}
\end{gathered}
$$

All the diagonal elements of the quadrupole moment tensor for TPA1 and TPA3 are negative, indicating that the negative charge distribution is farther removed from the molecular center of the nuclear charges. The off-diagonal tensor elements $Q_{i j}$
Table 2. Quadrupole moments (in Debye $\AA \AA$ ) of TPA1 and TPA 3

\begin{tabular}{ccccccccc}
\hline Dyes & $Q_{X X}$ & $Q_{Y Y}$ & $Q_{Z Z}$ & $Q_{X Y}$ & $Q_{X Z}$ & $Q_{Y Z}$ & $Q_{i i}$ & $Q$ \\
\hline TPA1 & -130.5 & -215.3 & -254.9 & -33.9 & 31.6 & 93.1 & -200.2 & 84.8 \\
TPA3 & -214.3 & -286.9 & -298.5 & -55.1 & 48.2 & 90.3 & -266.6 & 72.6 \\
\hline
\end{tabular}

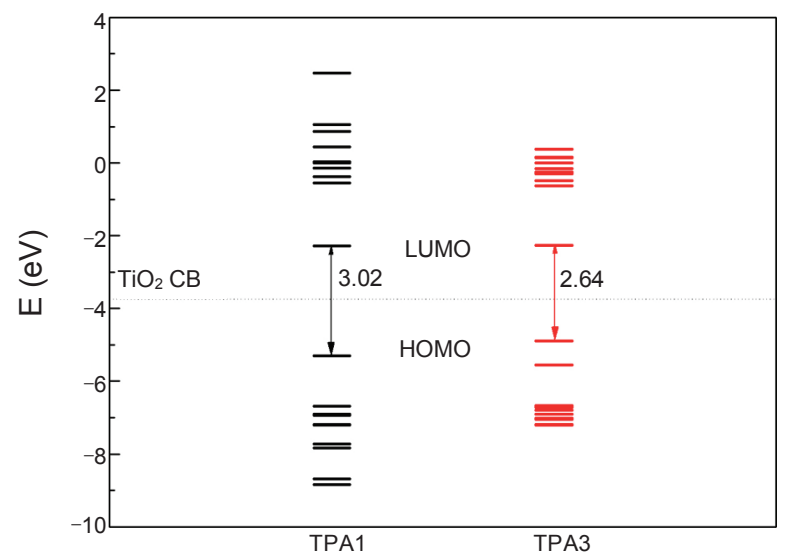

Figure 2. Frontier molecular orbital energies computed for TPA1 and TPA3 together with the $\mathrm{TiO}_{2}$ anatase (101) conduction band.

vanish whenever the molecule has a plane of symmetry perpendicular to either one of the coordinates $i$ or $j$. The values of the off-diagonal elements $Q_{X Y}$ and $Q_{X Z}$ of TPA1 and TPA3 are relatively lower, which can be attributed to its symmetric plane nearly perpendicular to the $\mathrm{x}$-axis, as shown in Fig. 1. It is noteworthy that the dipole and quadrupole moment values of TPA3 are larger than those of TPA1, revealing that the 4-diphenylamino-diphenylaniline group is indeed a stronger electron donor with respect to the diphenylaniline group.

The NBO analysis was employed to characterize the ICT in TPA1 and TPA3. The natural charges of diphenylaniline group (donor) and cyanoacrylic acid (acceptor) in TPA1 are 0.143 and $-0.143 \mathrm{e}$, whereas those of diphenylamino, diphenylaniline and cyanoacrylic acid in TPA3 are $-0.121,0.271$ and $-0.150 \mathrm{e}$, respectively. The above data reveal that the diphenylamino unit in TPA3 is not an effective electron donor unit, but the introduction of the diphenylamino unit can enhance both the electron-donating capability of the diphenylaniline group and the electron-drawing capability of the cyanoacrylic acid (in agreement with the previously discussed results in dipole moments).

The frontier molecular orbital (MO) contribution is very important in determining the charge-separated states of dye sensitizers. To create an efficient charge-separated state, the highest occupied MO (HOMO) must be localized on the extended donor moiety and the lowest unoccupied MO (LUMO) on the acceptor moiety. The MO energies and isodensity plots of TPA1 and TPA3 are shown in Figs. 2 and 3, respectively. For TPA1, the HOMO, lying at $-5.31 \mathrm{eV}$, is a delocalized $\pi$ orbital over the cyano group through the diphenylaniline whereas the HOMO-1, $1.39 \mathrm{eV}$ below the HOMO, is delocalized over the entire molecule. The HOMO-2, $1.61 \mathrm{eV}$ below the HOMO, is a $\pi$ orbital localized in the phenyl groups of diphenylaniline, whereas the 


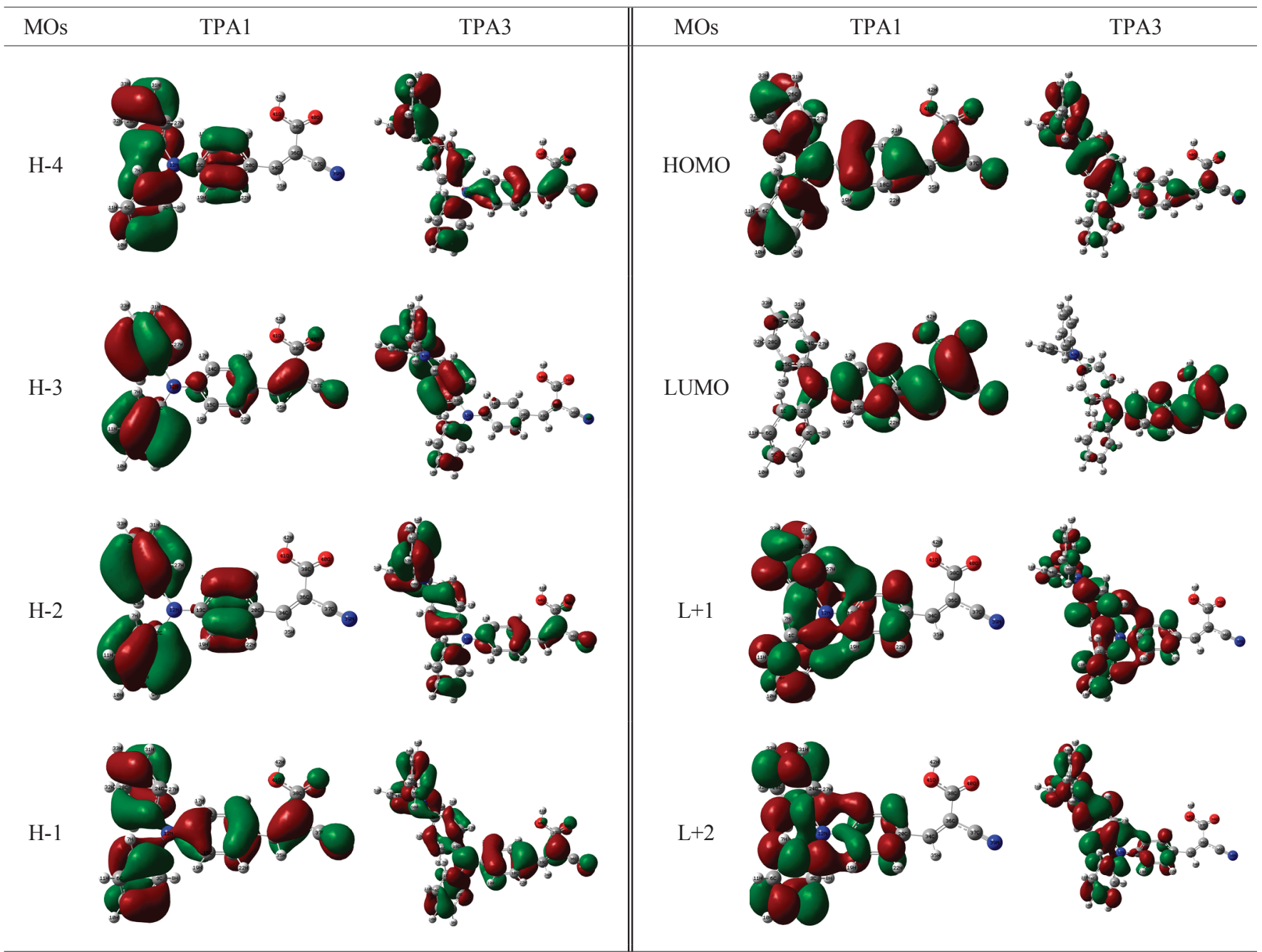

Figure 3. Isodensity plots (isodensity contour $=0.02$ a.u.) of the frontier orbitals of TPA1 and TPA3.

HOMO-3, $1.63 \mathrm{eV}$ below the HOMO, is delocalized in the cyano group and the phenyl groups of diphenylaniline with less contributions in the phenyl group linked to the cyanoacrylic acid group. The LUMO, lying at $-2.29 \mathrm{eV}$, is a $\pi^{*}$ orbital localized in the cyanoacrylic acid and the connected phenyl in diphenylaniline, whereas the LUMO+1 and LUMO+2, lying 1.74 and $1.90 \mathrm{eV}$ above the LUMO, respectively, are also $\pi^{*}$ orbitals mainly localized in the diphenylaniline group. As to TPA3, the HOMO, lying at $-4.90 \mathrm{eV}$, is delocalized over the cyano group through the 4-diphenylamino-diphenylaniline group with sizable contributions arising from the diphenylamino unit, indicating the strong electron injection character of 4-diphenylamino-diphenylaniline group. The HOMO-1 and HOMO2, lying 0.65 and $1.77 \mathrm{eV}$ below the HOMO, respectively, are $\pi$ orbitals delocalized over the entire molecule; whereas the HOMO-3, lying $1.82 \mathrm{eV}$ below the HOMO, is mainly localized in the diphenylamino unit. The LUMO, LUMO+1 and LUMO+ 2, 2.64, 4.27 and $4.41 \mathrm{eV}$ above the HOMO, respectively, are similar to those of TPA1.

Apparently, in both TPA1 and TPA3, the HOMO is quite delocalized on the extended donor moieties, while the LUMO is essentially centered on the respective acceptor groups. Thus, the HOMO-LUMO excitation on TPA 1 and TPA 3 induced by light irradiation could move the electron distribution from the donor moieties to the anchoring/acceptor moieties, consequently favoring electron injection from dye to $\mathrm{TiO}_{2}$. The LUMO is practically isoenergetic in the two compounds, and only a very small energy deviation is computed between TPA1 and TPA3 $(0.03 \mathrm{eV})$. On the contrary, the HOMO of TPA3 is computed at a significantly higher energy (roughly $0.32 \mathrm{eV}$ ) than that of TPA3, indicating that the 4-diphenylamino-diphenylaniline group is indeed a stronger electron donor with respect to the diphenylaniline group (in agreement also with the previously discussed results in dipole moments). Furthermore, the introduction of the diphenylamino unit enhances the spatial extent of the $\pi$ conjugation system and is expected to produce sizable effects on the absorption spectra.

The HOMO-LUMO gap of TPA1 and TPA3 is 3.02 and 2.64 $\mathrm{eV}$, respectively. The calculated HOMO and LUMO energies of the bare $\mathrm{Ti}_{38} \mathrm{O}_{76}$ cluster as a model for nanocrystalline are -6.55 and $-2.77 \mathrm{eV}$, respectively, resulting in a HOMO-LUMO gap of $3.78 \mathrm{eV}$, and the lowest transition is reduced to $3.20 \mathrm{eV}$ according to TD-DFT, which is slightly smaller than typical band gap of $\mathrm{TiO}_{2}$ nanoparticles. ${ }^{4}$ Furthermore, the HOMO, LUMO and HOMO-LUMO gap of $\left(\mathrm{TiO}_{2}\right)_{60}$ cluster is $-7.52,-2.97$, and $4.55 \mathrm{eV}$ (B3LYP/VDZ), respectively. ${ }^{42}$ Usually an energy 
Table 3. Electronic transition configurations, computed excitation energies and oscillator strengths $(f)$ for the main optical transitions in visible and near- $\mathrm{UV}$ region of TPA1 and TPA3 in methanol solution $(\mathrm{H}=\mathrm{HOMO}, \mathrm{L}=\mathrm{LUMO}, \mathrm{L}+1=\mathrm{LUMO}+1$, etc.)

\begin{tabular}{|c|c|c|c|c|}
\hline Dye & Configuration & $\begin{array}{c}\text { Excitation energy } \\
(\mathrm{eV} / \mathrm{nm})\end{array}$ & $f$ & Assign. \\
\hline \multirow{7}{*}{ TPA1 } & $\mathrm{H} \rightarrow \mathrm{L}(+85 \%)$ & $2.86 / 434.2$ & 1.0000 & \multirow{7}{*}{$\pi \rightarrow \pi^{*}$} \\
\hline & $\mathrm{H} \rightarrow \mathrm{L}+1(+47 \%) ; \mathrm{H}-2 \rightarrow \mathrm{L}(+28 \%)$ & $4.12 / 300.8$ & 0.0148 & \\
\hline & $\mathrm{H}-1 \rightarrow \mathrm{L}(+89 \%)$ & $4.20 / 295.4$ & 0.1691 & \\
\hline & $\mathrm{H} \rightarrow \mathrm{L}+1(+46 \%) ; \mathrm{H}-2 \rightarrow \mathrm{L}(+28 \%) ; \mathrm{H}-5 \rightarrow \mathrm{L}(+17 \%) ; \mathrm{H} \rightarrow \mathrm{L}+2(+8 \%)$ & $4.31 / 287.7$ & 0.0684 & \\
\hline & $\mathrm{H}-3 \rightarrow \mathrm{L}(+91 \%)$ & $4.41 / 281.3$ & 0.0473 & \\
\hline & $\mathrm{H} \rightarrow \mathrm{L}+2(+72 \%) ; \mathrm{H}-2 \rightarrow \mathrm{L}(18 \%)$ & $4.43 / 279.7$ & 0.0940 & \\
\hline & $\mathrm{H}-5 \rightarrow \mathrm{L}(+44 \%) ; \mathrm{H}-2 \rightarrow \mathrm{L}(31 \%) ; \mathrm{H} \rightarrow \mathrm{L}+2(7 \%)$ & $4.48 / 276.7$ & 0.0463 & \\
\hline \multirow{6}{*}{ TPA3 } & $\mathrm{H} \rightarrow \mathrm{L}(+93 \%)$ & $2.49 / 497.5$ & 0.5344 & \multirow[t]{6}{*}{$\pi \rightarrow \pi^{*}$} \\
\hline & $\mathrm{H}-1 \rightarrow \mathrm{L}(+89 \%)$ & $3.14 / 395.3$ & 0.6259 & \\
\hline & $\mathrm{H} \rightarrow \mathrm{L}+1(+88 \%)$ & $3.81 / 325.5$ & 0.2863 & \\
\hline & $\mathrm{H} \rightarrow \mathrm{L}+2(+86 \%)$ & $3.91 / 316.8$ & 0.2677 & \\
\hline & $\mathrm{H} \rightarrow \mathrm{L}+3(+84 \%)$ & $4.12 / 300.6$ & 0.2460 & \\
\hline & $\mathrm{H}-2 \rightarrow \mathrm{L}(+58 \%) ; \mathrm{H}-3 \rightarrow \mathrm{L}(+16 \%) ; \mathrm{H}-4 \rightarrow \mathrm{L}(+10 \%)$ & $4.24 / 292.6$ & 0.1165 & \\
\hline
\end{tabular}

gap more than $0.2 \mathrm{eV}$ between the LUMO of the dye and the $\mathrm{CB}$ of $\mathrm{TiO}_{2}$ is necessary for effective electron injection. ${ }^{9}$ Taking into account of the cluster size effects and the calculated HOMO, LUMO, HOMO-LUMO gap of TPA1, TPA3, $\mathrm{Ti}_{38} \mathrm{O}_{76}$ and $\left(\mathrm{TiO}_{2}\right)_{60}$ clusters, it can be found that the HOMO energies of these two dyes fall within the $\mathrm{TiO}_{2}$ gap. The above data also reveal the sensitized mechanism: the interfacial electron transfer between the $\mathrm{TiO}_{2}$ electrode and the dye sensitizers TPA1 and TPA3 are electron injection processes from the photo-excited dyes to the semiconductor CB. This is a kind of typical interfacial electron transfer reaction. ${ }^{43}$ Relatively large energy gaps between the LUMO energies of these dyes and the semiconductor $\mathrm{CB}$ would be beneficial to the photovoltaic conversion properties.

Absorption spectra. The UV-vis spectra of TPA1 and TPA3 were measured in solution, and both consist of a very intense and well isolated absorption band in the $400-600 \mathrm{~nm}$ region and of a less intense band in the $300 \mathrm{~nm}$ region. ${ }^{34}$ The spectrum of TPA3 is red-shifted in comparison with that of TPA1 as well as stronger and broader around $300 \mathrm{~nm}$, which is due to the expansion of $\pi$ conjugation systems by introducing the diphenylamino unit to p-position of the basic triphenylamine structure. In order to understand electronic transitions of TPA1 and TPA3, TD-DFT calculations on absorption spectra in methanol were performed with three kinds of hybrid functional B3LYP, MPW1PW91 and PEB1PBE based on the optimized geometries, taking the 30 lowest spin-allowed singlet-singlet transitions into account. It can be found that the hybrid functional PBE1PBE and MPW1PW91 are more suitable than B3LYP for calculating absorption spectra of the present triphenylamine dyes TPA1 and TPA3.

The vertical excitation energy and oscillator strength along with the main excitation configuration of TPA1 and TPA3 computed by PBE1PBE are listed in Table 3. The simulated UV-vis absorption spectra of TPA1 and TPA3 are shown in Fig. 4. The overall spectral red-shift when going from TPA1 to TPA3 is correctly reproduced. For TPA1, both qualitative and quan-

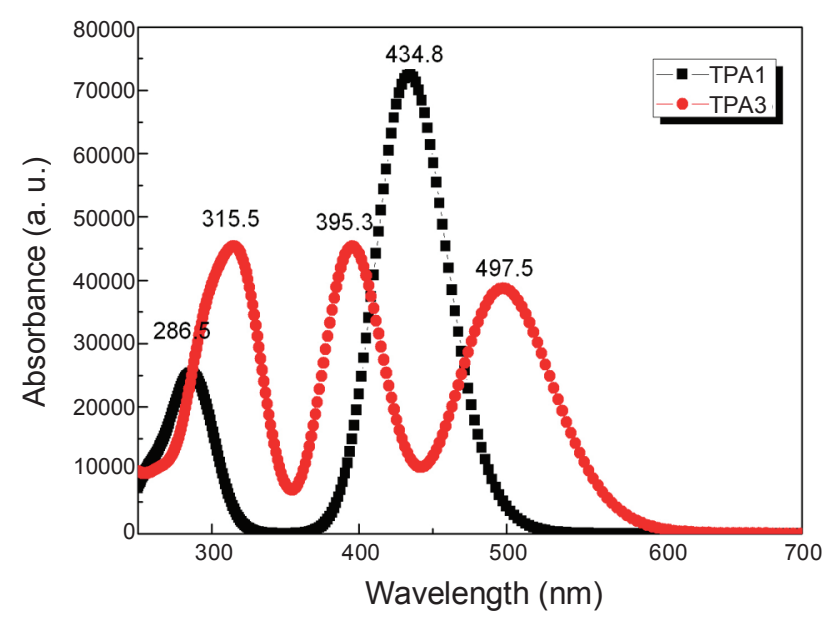

Figure 4. Simulated absorption spectra of TPA1 and TPA3 in methanol solution at the PBE1PBE/6-31g(d) level.

titative agreements between the experimental and computed bands can be obtained. The first band clearly corresponds to the previously described HOMO-LUMO transition, and is of ICT character thus possessing high transition intensity. The second and less intense band also corresponds to a $\pi$ - $\pi^{*}$ transition with a strong HOMO-1 to LUMO character. Since the HOMO-1 is delocalized in the entire molecule, this band also has an ICT character.

As to TPA3, there are two moderate bands computed in the 400 - $600 \mathrm{~nm}$ region, corresponding to the HOMO and HOMO-1 to LUMO transition, respectively. Consequently, the experimental band of TPA3 centered at $477 \mathrm{~nm}$ is considered as the combination of these two transitions, which probably results from the relatively small energy discrepancy between the HOMO and HOMO-1. The band in the $300 \mathrm{~nm}$ region is well reproduced, which corresponds to the HOMO to LUMO+2 transition. However, this transition does not benefit ICT from the donor to acceptor moiety since the $\mathrm{LUMO}+2$ is primarily localized in the donor moiety. 


\section{Conclusions}

The geometric and electronic structures of two dyes containing diphenylaniline and 4-diphenylamino-diphenylaniline as donor moiety (TPA1 and TPA3) have been computed using 6-31 $\mathrm{g}(\mathrm{d})$ basis set at density functional B3LYP level. The UV-vis absorption spectra have been simulated by TD-DFT calculations. The calculated geometries indicate that the strong conjugate effects are formed in TPA1 and TPA3, which is beneficial to the intramolecular charge transfer. The NBO analysis suggests that there are some electrons transferred from the electron donor to the acceptor in TPA1 and TPA3, and the 4-diphenylamino-diphenylaniline group is a stronger donor with respect to the diphenylaniline group. The HOMO energy levels are computed to be -5.31 and $-4.90 \mathrm{eV}$, while the LUMOs are -2.29 and $-2.26 \mathrm{eV}$ for TPA1 and TPA3, respectively, pointing out that the electron transfer from the excited dyes to the $\mathrm{TiO}_{2}$ conduction band is available. On the basis of the TDDFT results, the experimental absorption band in the $400-600 \mathrm{~nm}$ region of TPA 1 is assigned to the HOMO $\rightarrow$ LUMO transition, while this of TPA3 is considered as the combination of the HOMO and HOMO-1 to LUMO transition.

Acknowledgments. This work was supported by the Foundation of Wuhan University of Science \& Engineering (No. 2009003), the Natural Science Foundation of Hubei Province (No. 2008CDB261) and China (No. 51003082), the Key Project of Science and Technology Research of Ministry of Education (No. 208089) and the Educational Commission of Hubei Province (Q20101606). The authors gratefully wish to express their thanks to the reviewers for critically reviewing the manuscript and making important suggestions.

\section{References}

1. O'Regan, B.; Grätzel, M. Nature 1991, 353, 737.

2. Nazeeruddin, M. K.; Kay, A.; Rodicio, R.; Humpbry-Baker, R.; Miiller, E.; Liska, P.; Vlachopoulos, N.; Grätzel, M. J. Am. Chem. Soc. 1993, 115, 6382 .

3. Nazeeruddin, M. K.; Péchy, P.; Renouard, T.; Zakeeruddin, S. M.; Humphry-Baker, R.; Comte, P.; Liska, P.; Cevey, L.; Costa, E.; Shklover, V.; Spiccia, L.; Deacon, G. B.; Bignozzi, C. A.; Grätzel, M. J. Am. Chem. Soc. 2001, 123, 1613.

4. Nazeeruddin, M. K.; Angelis, F. D.; Fantacci, S.; Selloni, A.; Viscardi, G.; Liska, P.; Ito, S.; Takeru, B.; Grätzel, M. J. Am. Chem. Soc. 2005, 127, 16835.

5. Gao, F.; Wang, Y.; Shi, D.; Zhang, J.; Wang, M.; Jing, X.; Humphry-Baker, R.; Wang, P.; Zakeeruddin, S. M.; Grätzel, M. J. Am. Chem. Soc. 2008, 130, 10720.

6. Chen, C.-Y.; Wang, M.; Li, J.-Y.; Pootrakulchote, N.; Alibabaei, L.; Ngoc-le, C.-h.; Decoppet, J.-D.; Tsai, J.-H.; Grätzel, C.; Wu, C.-G.; Zakeeruddin, S. M.; Grätzel, M. ACS Nano 2009, 3, 3103.

7. Amao, Y.; Komori, T. Biosensors Bioelectron. 2004, 19, 843.

8. Horiuchi, T.; Miura, H.; Sumioka, K.; Uchida, S. J. Am. Chem. Soc. 2004, 126, 12218.

9. Hara, K.; Kurashige, M.; Dan-oh, Y.; Kasada, C.; Shinpo, A.; Suga, S.; Sayama, K.; Arakawa, H. New J. Chem. 2003, 27, 783.

10. Horiuchi, T.; Miura, H.; Uchida, S. Chem. Comm. 2003, 3036.

11. Horiuchi, T.; Miura, H.; Uchida, S. J. Photochem. Photobiol. A: Chem. 2004, 164, 29.

12. Kitamura, T.; Ikeda, M.; Shigaki, K.; Inoue, T.; Anderson, N. A.; Ai, X.; Lian, T.; Yanagida, S. Chem. Mater. 2004, 16, 1806.

13. Hagberg, D. P.; Yum, J.-H.; Lee, H.; Angelis, F. D.; Marinado, T.; Karlsson, K. M.; Humphry-Baker, R.; Sun, L.; Hagfeldt, A.; Grä- tzel, M.; Nazeeruddin, M. K. J. Am. Chem. Soc. 2008, 130, 6259.

14. Tian, H.; Yang, X.; Chen, R.; Zhang, R.; Hagfeldt, A.; Sun, L.J. Phys. Chem. C 2008, 112, 11023.

15. Mishra, A.; Fischer, M. K. R.; Bäuerle, P. Angew. Chem. Int. Ed. 2009, 48, 2474.

16. Barolo, C.; Nazeeruddin, M. K.; Fantacci, S.; Di Censo, D.; Comte, P.; Liska, P.; Viscardi, G.; Quagliotto, P.; De Angelis, F.; Ito, S.; Gratzel, M. Inorg. Chem. 2006, 45, 4642.

17. Onozawa-Komatsuzaki, N.; Kitao, O.; Yanagida, M.; Himeda, Y.; Sugihara, H.; Kasuga, K. New J. Chem. 2006, 30, 689.

18. Monat, J. E.; Rodriguez, J. H.; McCusker, J. K. J. Phys. Chem. A 2002, 106, 7399.

19. Fantacci, S.; De Angelis, F.; Selloni, A. J. Am. Chem. Soc. 2003, $125,4381$.

20. Angelis, F. D.; Fantacci, S.; Selloni, A.; Nazeeruddin, M. K. Chem. Phys. Lett. 2005, 415, 115.

21. Zhang, X.; Zhang, J.-J.; Xia, Y.-Y.J. Photochem. Photobiol. A: Chem. 2007, 185, 283.

22. Xu, Y.; Chen, W.-K.; Cao, M.-J.; Liu, S.-H.; Li, J.-Q.; Philippopoulos, A. I.; Falaras, P. Chem. Phys. 2006, 330, 204.

23. Kurashige, Y.; Nakajima, T.; Kurashige, S.; Hirao, K.; Nishikitani, Y. J. Phys. Chem. A 2007, 111, 5544.

24. Hara, K.; Sato, T.; Katoh, R.; Furube, A.; Ohga, Y.; Shinpo, A.; Suga, S.; Sayama, K.; Sugihara, H.; Arakawa, H. J. Phys. Chem. B 2003, 107, 597.

25. Zhang, X.; Zhang, J.-J.; Xia, Y.-Y.J. Photochem. Photobiol. A: Chem. 2008, 194, 167

26. Liu, Z. J. Mol. Struct. (Theochem) 2008, 862, 44.

27. Xu, J.; Zhang, H.; Wang, L.; Liang, G.; Wang, L.; Shen, X.; Xu, W. Monatsh. Chem. 2010, 141, 549.

28. Alexander, B. D.; Dines, T. J.; Longhurst, R. W. Chem. Phys. 2008, $352,19$.

29. Lee, C.; Sohlberg, K. Chem. Phys. 2010, 367, 7.

30. Ma, R.; Guo, P.; Cui, H.; Zhang, X.; Nazeeruddin, M. K.; Grätzel, M. J. Phys. Chem. A 2009, 113, 10119.

31. Gao, Y.; Sun, S.; Han, K. Spectrochim. Acta A: Mol. Biomol. Spectrosc. 2009, 71, 2016.

32. Xu, J.; Liang, G.; Wang, L.; Xu, W.; Cui, W.; Zhang, H.; Li, Z. J. Serb. Chem. Soc. 2010, 75, 259.

33. Ning, Z.; Tian, H. Chem. Comm. 2009, 5483.

34. Erten-Ela, S.; Marszalek, M.; Tekoglu, S.; Can, M.; Icli, S. Curr. Appl. Phys. 2010, 10, 749

35. Frisch, M. J.; Trucks, G. W.; Schlegel, H. B.; Scuseria, G. E.; Robb, M. A.; Cheeseman, J. R.; Montgomery, J. A., Jr.; Vreven, T.; Kudin, K. N.; Burant, J. C.; Millam, J. M.; Iyengar, S. S.; Tomasi, J.; Barone, V.; Mennucci, B.; Cossi, M.; Scalmani, G.; Rega, N.; Petersson, G. A.; Nakatsuji, H.; Hada, M.; Ehara, M.; Toyota, K.; Fukuda, R.; Hasegawa, J.; Ishida, M.; Nakajima, Y.; Honda, Y.; Kitao, O.; Nakai, H.; Klene, M.; Li, X.; Knox, I. E.; Hratchian, H. P.; Cross, J. B.; Bakken, V.; Adamo, C.; Jaramillo, J.; Gomperts, R.; Stratmann, R. E.; Yazyev, O.; Austin, A. J.; Cammi, R.; Pomelli, C.; Ochterski, J. W.; Ayala, P. Y.; Morokuma, K.; Voth, G. A.; Salvador, P.; Dannenberg, J. J.; Zakrzewski, V. G.; Dapprich, S.; Daniels, A. D.; Strain, M. C.; Farkas, O.; Malick, D. K.; Rabuck, A. D.; Raghavachari, K.; Foresman, J. B.; Ortiz, J. V.; Cui, Q.; Baboul, A. G.; Clifford, S.; Cioslowski, J.; Stefanov, B. B.; Liu, G.; Liashenko, A.; Piskorz, P.; Komaromi, I.; Martin, R. L.; Fox, D. J.; Keith, T.; AlLaham, M. A.; Peng, C. Y.; Nanayakkara, A.; Challacombe, M.; Gill, P. M. W.; Johnson, B.; Chen, W.; Wong, M. W.; Gonzalez, C.; Pople, J. A. Gaussian Inc.: Wallingford CT, 2004.

36. Becke, A. D. J. Chem. Phys. 1993, 98, 5648.

37. Lee, C.; Yang, W.; Parr, R. G. Phys. Rev. B 1988, 37, 785.

38. Gorelsky, S. I. University of Ottawa: Ottawa, Canada, 2010

39. Cossi, M.; Barone, V.; Cammi, R.; Tomasi, J. Chem. Phys. Lett. 1996, 255, 327.

40. Barone, V.; Cossi, M. J. Phys. Chem. A 1998, 102, 1995.

41. Howie, W. H.; Claeyssens, F.; Miura, H.; Peter, L. M. J. Am. Chem. Soc. 2008, 130, 1367.

42. Lundqvist, M. J.; Nilsing, M.; Persson, P.; Lunell, S. Int. J. Quantum Chem. 2006, 106, 3214.

43. Watson, D. F.; Meyer, G. J. Annu. Rev. Phys. Chem. 2005, 56, 119. 